\title{
INNOVATIVE METHODS OF TEACHING \& LEARING ELECTRONICS ENGINEERING
}

\author{
Shrinivas A. Patil ${ }^{1}$, Saurabh R Prasad ${ }^{2}$ \\ ${ }_{1,2}$ Department of Electronics and Telecommunication Engineering \\ DKTE Society's Textile and Engineering Institute, Ichalkaranji \\ Kolhapur, Maharashtra, India \\ ${ }^{1}$ shrinivasapatil@gmail.com, \\ ${ }^{2}$ saurabhprasad21@gmail.com
}

\begin{abstract}
India is a country with huge populations and similarly number of universities and educational institutes across the country. As per All India Survey of higher education in 2013 conducted by Ministry of Human Resource development there are more than 642 Universities, 34908 colleges and 11356 stand alone institutions. Still there is not even a single educational institute from India which is listed in top 100 in the world. Thus there is an urgent need for the transformation of Indian educational system. This paper evaluates the traditional methods of teaching and suggests different innovating teaching methods. With traditional methods of teaching and learning the present day learners feel uncomfortable a bit. This paper portrays combining this two types how we can make our teaching more effective. The suggested methodologies are applicable to all the streams of knowledge in general but to Electronics engineering in particular. Ultimately whatever the teaching methodology we adopt, but teaching must be learner centric.
\end{abstract}

Keywords: Chalk and talk method, Innovative methods, outcome based education, learner centric approach, active learning, multimedia animation

\section{Saurabh R Prasad}

Electronics and Telecommunication Engineering Department,

DKTE Society's Textile and Engineering Institute, "Rajwada", Ichalkaranji, Kolhapur, India

Email: saurabhprasad21@gmail.com

\section{INTRODUCTION}

India enjoys the appreciation for being the motherland for one of the most ancient educational system in the world. The "Guru-Shishya Parampara" has been an inevitable part of education in the ancient Indian Culture. This involved the tradition of a living and learning relationship between the Guru and Shishya (Student), signifying the emotional, intellectual and spiritual bonding between them. With the help of this tradition, India could enjoy the position of knowledge kingdom of the world. India hailed the oldest universities in the world, namely Nalanda and Takshashila, the later one is now in Pakistan (Arunachalam, 2010). In ancient day people from different foreign countries used to come to India for knowledge and education. But what situation is today? As per All India Survey of higher education in 2013 conducted by Ministry of Human Resource development, there are more than 642 Universities, 34908 colleges and 11356 stand alone institutions. Still there is not even a single educational institute from India which is listed in top 100 in the world. So a transformation in education system is urgently required.

Mahatma Gandhi said, "Education is an all kind development of an individual". Education is a light that shows the mankind the right direction to surge. The purpose of education is not just making a student literate but adds rationale thinking, and self sufficiency. Education is an integral part of growth of an individual and helps them become good citizens and build character. Education is an engine for the growth and progress of any society. The higher education system contributes to the prosperity and progress of the nation in all walks of life. It not only imparts knowledge, skills and inculcates values, but is also responsible for building human capital. Today is the era of science and technology and there is a great need to improve quality of education. This can be possible by brining fundamental changes through innovative techniques by which teachers can provide students 
centered learning environment that can make learning process interesting and understandable to the young learners.

\section{LITERATURE SURVEY}

Steven McGee and Bruce Howard in their work compare conventional method of teaching with the Horse Race and emphasis that the conventional methods are not good for the overall growth of students, rather they create only a competing environment (McGee and Howard, 1998). Doyle in 1983 studied the impact of academic learning through indirect tasks where the learners were redirected to focus their attention to alternate tasks rather direct study of the curriculum (Doyle, 1983). He concluded that learning can be influenced by targeting and applying different ways of processing information and focusing the attention towards a particular task. Croker and Algina in 1986 assert in their work the individual needs of the students that cannot be fulfilled with one standard teaching method as every student comes from different background and possess different questions about the things being taught and have a different focus towards the environment around him or her (Crocker and Algina, 1986). So until and unless the things get cleared in the mind of students, the learning cannot be gauged, rather conventional methods are mostly measuring the memorizing skills of the students instead of bringing clarity in their minds.

In traditional teaching method, the instructor is the center delivering factual knowledge to the whole group of learners and having a complete authority in the classroom. The students have a minimum role to play here and the just at the receiving end of the transmission (Orlich et al., 2012). The traditional approach is least practical and applied and more theoretical and memorizing (Teo and Wong, 2000). On the other hand activity based learning encourages student to learn real life problems based on applied knowledge and keep the interest and understanding of the students at its highest level (Boud, and Feletti, 1998). We have to convert education into a sport and learning process has to generate interest in the students and motivate them to stay back in the institution than to run away from it. Education should become a fun and thrill to them rather than burden and boredom.

The learner centered teaching methods are the cooperative endeavors to be followed both by the teacher and students. Such approaches remove passivity, dullness, non performance of the students. Teachers must have accurate knowledge of the subject, ability to bring the subject matter to the level of students' understanding, self confidence, ability of expression, ability in questioning and respect for students' opinion. The methods like Flanders's interaction analysis may be employed for better teaching (Amidon and Flanders, 1971).

Students actively learn by observing and performing activities, the process of learning is far more accelerated when a practical implementation is associated and the learner is benefited with the applied knowledge and skills and it also involves trial and error at times during selfexploration. It's more effective if the students are made to perform rather just asked to remember some information. The applied and implicit knowledge should be the ultimate goal of the education system. A typical classroom environment with a presentation from the course teacher does not promote learners to participate and does not build a required involvement of the students. Most of the learners just copy the notes from lecture or board considering it part of their responsibility being in the class but it does not build their engagement with the course being taught. This typical environment only promotes only a fraction of students who start thinking at their own and raise questions. Educationists of today find this method limiting and less effective as the learners may lose their concentration within small time due to passive role and less participation. Most of students feel boredom and monotony in the class due to same usual teaching patterns of the teachers. These students sometimes produce alarmingly poor results in the exams. The limitations of traditional method are described below.

- Teaching in classroom using chalk and talk is "one way flow" of information.

- Teachers often continuously talk for an hour without knowing students response, feedback and queries

- Course material is limited to the pre-prepared lectures and text books

- Insufficient elements of interest and engagement for the learners

- Applied and real life knowledge is least discussed and focus is purely based theory

- The system promotes memorizing skills of student and least concerned with the understanding

- More emphasis has been given on theory without any practical and real life time situations

- Marks oriented rather than knowledge oriented

3. MeThodology

The traditional or innovative methods of teaching are critically examined, evaluated and some modifications in the delivery of knowledge are suggested. The probable modifications that can be included in traditional teaching methods are suggested. Teaching only the definitions, derivations, theorems, rules etc which are mostly occurring in almost all subjects of science and technology is found to be boring by most students and because of this that they lose interest in learning the subject. Students of higher classes who most usually have grown up so far with traditional methods generally tend to yield poorer results if the same traditional method is continued, but their performance improves with innovative methods. This has already been proven by many researchers that 
innovative methods like use of Information and Communication Technology (ICT), educational video, Power Point Presentation, and Internet, etc help the students learn better and also it keeps their interest. This paper will provide a few of such methods to teach the subjects of Engineering and technology. We have conducted an experiment to test effectiveness of innovative teaching. The innovative technique adopted in our experimentation was the use of Multimedia Animations for teaching "Working of Magnetron" in Microwave Engineering course of BE (ETC) students.

\section{INNOVATIVE TOOLS}

\section{I hear and I forget.}

I see and I believe.

I do and I understand. - Confucius

The above mentioned famous statement clearly indicates the importance of using different tools rather than plain chalk and talk lecture. The impact of teaching in fact depends upon how many sensory organs are involved in the learning process. The innovative teaching methods aim at utilizing maximum sensory organs in learning activities. In traditional teaching, few students are declared as intelligent, few as average and remaining as poor. As per theory of multiple intelligence most of them can be intelligent with respect to teaching methodology that suits to their intelligence. The Theory of Multiple Intelligences put forth by Howard Gardner differentiates intelligence into specific "modalities", rather than seeing intelligence as dominated by a single general ability (Gardner, 2011). Gardner chose eight learning abilities those are mentioned below.

$\begin{array}{ll}\text { - } & \text { musical-rhythmic } \\ \text { - } & \text { visual-spatial } \\ \text { - } & \text { verbal-linguistic } \\ \text { - } & \text { logical-mathematical } \\ \text { - } & \text { interpersonal } \\ \text { - } & \text { intrapersonal } \\ \text { - } & \text { naturalistic }\end{array}$

As per this theory most of the students are intelligent in at least one of above traits.

The effectiveness of the class-room teaching largely depends upon the teaching methodology adopted. The various innovative teaching methods are described below.

\section{A. Multimedia and Audio-Visual aid}

Multimedia, is the combination of various digital media types such as text, images, audio and video, into an integrated multi-sensory interactive application or presentation to convey information to an audience. Fortunately, there are many multimedia technologies that are available for developers to create these innovative and interactive multimedia applications (Snyder and Vaughan, 1998). These technologies include Adobe Photoshop and Premier to create edit graphics and video files, SoundForge and 3D Studio Max to create and edit sound and animation files. Especially for Electronics Engineering where there is a need of visualization, for example, in teaching Working of Transistor, Diode, Microwave Tubes like Klystron, Magnetron etc, the use of multimedia is exceptionally good. Similarly, this method can be used for teaching complex concepts particularly in Electronics and Telecommunication Engineering such as Electromagnetic Wave Propagation, Radiation from Antenna etc.

We can use audio-visual aid to show video lectures, animations, Educational Songs etc. This method imparts knowledge of renowned personalities in the concerned subjects to students by playing their lectures. Computer is an inevitable tool which can be used for variety of applications in teaching; for example showing power point presentation, and showing three dimension graphics to make our teaching effective and easy. Computer can be used to solve Linear Programming Problems with the help of solver available in Excel. Over Head Projector (OHP)/ LCD Projector etc can be used along with computer.

\section{B. Problem Solving Approach}

Traditional educational approaches have resulted in a mismatch between what is taught to the students and what the industry needs. Therefore many institutions are moving towards problem based learning as a solution to producing graduates who think critically and analytically. Problem-based learning is becoming increasingly popular in educational institutions as a tool to address the inadequacies of traditional teaching. Since these traditional approaches do not encourage students to question what they have learnt or to associate with previously acquired knowledge, problem-based learning is seen as an innovative measure to encourage students to learn how to learn via real-life problems (Wood, 2003).

\section{Enacting The Stories}

Stories form a very integral role in maintaining interest amongst audience. These stories help in keeping the students' interest alive as the story's end is something that every student wants to know. Any unfinished story always keeps the mind of the reader agitated. Therefore a good teacher should try to explain the concepts with the help of real or cooked stories.

\section{Teaching Through Games}

This is a very interesting method of teaching. Students generally like games and want to play them more and more. Traditional methods dictate study and games to be separate but the fact remains that the students are more 
interested in playing games rather than sitting for study. Thus it is logical to combine these two aspects and solve the problem. The learning by means of games would help the students keep their interest in the subject. With this methodology, the learning process would continue almost throughout the day without the student getting tired or bored of studying. The different forms of game are described below:

1) Word Game/ Cross Word Puzzle: Here in class teacher can make two groups like a group of boy and a group of girl. Then a competition can be started amongst two groups to write maximum words, definition, terminology etc. pertaining to a particular subject.

2) Role Play: Here a complicated concept can be simplified with the help of role play. Science and Engineering courses have practicals which simplify understanding theoretical concepts. However for each and every theory, practicals are not possible. So, in such a situation, role play, an educational drama helps lot. Here few volunteers as per requirement are asked to play the game where each volunteer student will play certain role. For example in the concept of Working of Microprocessors, One volunteer will play the role of Accumulator; another will play the role of register, ALU, Clock etc.

\section{E. Mind Map}

Mind maps were developed in the late 60s by Tony Buzan as a way of helping students make notes that used only key words and images, but mind map can be used by teachers to explain concepts in an innovative way (Buzan, 2010). They are much quicker to make and much easier to remember and review because of their visual quality. The nonlinear nature of mind maps makes it easy to link and cross-reference different elements of the map.

\section{F. Competitions}

Most of the times competitions like debates and elocutions also help the students a lot in learning as the competitions keep them at the best. Also these competitions help them address large crowds which is again is a very important part of personality development. The other things which encourage active participation of students are conducting Seminar, Symposium, and Workshop, Pick and speak competition, Questioning, and Quiz contests.

\section{G. Peer Group/ Team Teaching}

One of the most visible approaches to peer learning comes out of cognitive psychology, and is applied within a "mainstream" educational framework. "Peer learning is an educational practice in which students interact with other students to attain educational goals." The peer group learning practice is popularly called as cooperative learning.

\section{H. Tutorial}

A tutorial is more interactive and specific than a book or a lecture and seeks to teach by example and supply the information to complete a certain task. Depending on the context a tutorial can take one of many forms, ranging from a set of instructions to complete a task to an interactive problem solving session.

\section{I. $\quad Z$ TO A APPROACH}

This approach attempts to explain the application part of a particular concept first. The teacher should explain the application of a particular concept first prior to teaching theorems, definitions etc about a concept. For example in Electronic communication subject while teaching Radar topic, first the practical applications of radar can be explained which will create interest amongst students, and then the theory behind it should be explained.

\section{J. Creative Assignments}

Up till now most of the techniques that we discussed required a greater amount of effort on the teacher's part. However, assignments need work at students' part and it helps them to learn something at their own. This method of approach is very appropriate for sciences and engineering disciplines.

\section{K. Humor In Teaching}

Everyone loves a teacher with an infectious sense of humor. Such teacher not only maintains cordial relations between professors and students, but also provides welcome relief while trying to follow a difficult lecture on a complicated subject. We are convinced by experience that using humor in teaching is a very effective tool for both the teacher and student.

\section{Brainstorming}

Brainstorming is a technique used to generate large number of ideas. The technique was devised by Alex Faickney Osborn and was widely used by business managers to generate ideas and to find out creative ways of resolving management crisis (Osborn, 1953). Currently this technique is extensively used for teaching-learning. Brain storming involves the use of different techniques like Problem Solving, Model Making, and Simplification. There are two types of brainstorming (based on the number of participants): Individual Brainstorming: This involves allotting a task theme and asking people to work on it individually. The individual ideas are then consolidated; and Group Brainstorming: In this method, groups consisting of about more than eight participants are formed for a said task.

\section{Case Study Method}

A case Study is an open-ended problem or situation that requires careful formulation. It brings chunks of reality into the classroom. This method is used for solving a difficult problem or in case of a dilemma without an 
obvious solution. The case study should be context-based, relevant and involve relatively realistic scenario or situation. The case study should be challenging but not too frustrating problem that motivates the learner to explore, investigate, and study a problem that encourages interaction among learners, facilitator and the outside world. It forces us to deal with a real life situation where we have to answer: - What do we do now?"

\section{N. Demonstration}

Demonstration involves a scientific experiment which is carried out for the purpose of illustrating principles, rather than for hypothesis testing or knowledge gathering. It is a technique which involves illustration with examples rather than simple explanation. In this technique, the learners observe, collect data, assist in setting experiment for the facilitator initially and later perform the given task independently.

\section{O. Group Discussion}

Group discussion or Panel discussion is a technique used in the teaching- learning process. It is a formal discussion or verbal exchange of ideas and opinions on a specific subject with a group consisting of 5 to 8 members. In this methodology, the group members are given a topic or a situation. After reflecting on the topic for few minutes, they are asked to discuss it amongst themselves.

\section{P. Use of models as a teaching aid}

Models are human inventions, based on an incomplete understanding of how nature works. It is a representation of an idea, object, event, process and system. Models play a crucial role in science and technology teaching.

\section{Q. Use of Smart Board}

The Smart Board is an interactive whiteboard that uses touch detection for user input in the same way as normal $\mathrm{PC}$ input devices. It is usually connected to a computer and a projector wirelessly or via USB or serial cables. A projector connected to the computer displays the desktop image on the interactive whiteboard. The whiteboard accepts touch input from a finger, pen or other solid object. Thus it converts into pdf document whatever professor writes onto board. Thus the soft copy of course material is automatically created that may be distributed to all students immediately after lecture through Bluetooth.

\section{R. Use of simulation software}

It is software designed to provide a realistic imitation of the controls and operation of a complex system. Simulators play highly important role in the curriculum of electronics engineering. Different simulators such as 8085 microprocessor simulator, Circuit Simulators like Proteus, MultiSim, OrCAD etc are effectively being used in our curriculum. Simulators give in depth working knowledge as well as system design level knowledge to the students.

\section{Learner Centric Methodologies}

The traditional education system of India is based on the Lord Macaulay's foundation. We can never blame the traditional teaching because the same has produced great scientists, engineers, and other professionals. Yet the effectiveness of traditional teaching can be improved. Following discussion suggests how the learner centric approach may be implemented to improve the traditional teaching.

\section{A. Lecturing Method}

In traditional teaching approach adopted by different teachers is categorized as below.

Authoritarian approach: Teachers prepare lectures and present them before students. There is no scope for interaction in the classrooms of such teachers. The only choice with the students is to accept the monotonous teaching.

Spontaneous approach: The element of spontaneity is being observed in the classroom transaction of a few teachers. The two way interaction between teachers and students stimulate the whole class to participate actively in the teaching-learning activities.

Mixed Approach: Some of the teachers make use of inter mixing of authoritarian as well as spontaneous approaches.

Plain Lecture method can be largely overcome by the teachers by adopting techniques like questioning, black-board working and dictating in the middle in order to overcome the monologue of the teachers. The purpose of group activity should be established jointly by the student and teacher. Group work has to be made participatory, and enjoyable. To make the lecture method effective, the teacher has to follow certain guidelines. While preparing the lecture certain points should be noted which are: a) objective should be kept in mind, b) Examples, Narration or description should be related with day-to-day life experiences of the students, c) Students participation should be encouraged by asking questions, clarifying the doubts and reviewing key points at frequent intervals.

\section{B. Unit Method}

A unit may be defined as a means of organizing material for instructional purposes which utilizes significant subject matter. The five steps viz. preparation, presentation, comparison, generalization and application are steps which the pupil is expected to recognize and state. In this method the effective learning takes place in an environment where goals are clearly perceived. Teacher should involve pupil in learning activities through active participation intellectually and physically and 
modify the pupil's behavior to the extent that they are able to cope with new problems and situations more competently.

\section{Project Method}

This method is highly used and very popular in Electronics Engineering. It deals with the many aspects of learning together. Projects have been defined as that form of coordinated activity that is directed towards the earning of a significant skill. It involves at least four steps of active learning viz. purposing, planning, executing and judging. The project should be purposeful, useful and practically applicable to the students, with clear, well defined objectives. The level of complexity of the project should match the ability level of the students.

\section{Laboratory Method}

In electronics engineering, almost all subjects have prescribed practical syllabus. The practicals are used to explain few important and challenging concepts. It places the primary emphasis upon the equipment and its use. In this method one proceeds from concrete to abstract. The success of this method depends on an able and skilled teacher as well as the availability of a well equipped laboratory.

\section{E. Problem Method}

Here learning is stimulated by the creation of challenging situations that demand solution. In the process of solving the problem the students required to gather data, analyze and interpret the information to arrive at a solution to the problem. Risk, T.M. defines problem solving as "Planned attack upon a difficulty or perplexity for the purposes of finding a satisfactory solution" (Risk, 1958). Its objective is to stimulate the reflective and creative thinking of the students and helps to learn how to act in a new situation.

\section{OTHER APProACH APART From TeACHING}

Apart from teaching, there are many things which are highly important in uplifting students in terms of understanding of complex concept, and other abilities of students. The various efforts expected to be adopted for the same are described below.

\section{A. Enrichment Programme}

To enrich our student's knowledge, we can focus beyond the syllabus also. For the better understanding, we can arrange expert lectures by industrialists and eminent persons.

\section{B. Remedial Teaching Programme}

After the feedback followed by evaluation remedial work must be there. Similarly for poor performers, some sort of extra coaching is needed.

\section{Library/ Self Study}

The independent study habits found in the teachers or students is to be nurtured by the institutions. The Readers club, Literacy club, Writer's Forum is to be formed to cultivate healthy practices in the colleges.

\section{Outcome Based Learning}

Whatever teaching tool we adopt, there should be some measures to ratify the effectiveness of that education system. Therefore we have adopted the concept of outcome based teaching. Here for each program (for example UG- Electronics and Telecommunication), Program Educational Objective and Program Objectives are well defined. Similarly for each course, Course Objectives are framed. Similarly the institute as well as the department has their Vision, and Mission clearly defined and also there is due interrelation between them. Finally we can calculate Program Outcome attainment using different tools that include Internal Test, Internal Practical and Oral Examination (POE), Continuous evaluation of Journal, Assignment, University POE, University theory exam, Course Exit Survey Analysis etc.

\section{EXPERIMENTAL RESULT}

An experiment was conducted to study the effectiveness of innovative teaching methods vis-a-vis traditional teaching method. For this experiment we selected BE (E\&T) class as a sample. The innovative methodology which we adopted is Use of Multimedia Animation. The 74 students in the class were segregated into two groups each of 37 students. The one group is called as control group and another called as experimental group. For going as close as possible to random sampling of students in these two groups, we segregated the students amongst two groups by drawing chits. The teachers teaching to these two groups were same to avoid any extraneous factor. The one topic from Microwave Engineering named "Working of Magnetron" was taught for 1 hour to both the groups. Control group was administered traditional teaching, and the experimental group was administered innovative teaching using Multimedia Animation. Then after periodic interval of time, how much the students could recall was tested by supplying them questionnaire of 10 MCQ type questions. The result of this experiment is given below.

Table 1. EXPERIMENTAL RESULT

\begin{tabular}{|l|l|l|}
\hline \multicolumn{2}{|c|}{ Table 1. EXPERIMENTAL RESULT } \\
\hline $\begin{array}{l}\text { Average No of MCQ questions } \\
\text { answered correctly after 1 month }\end{array}$ & $\begin{array}{l}\text { Control } \\
\text { Group }\end{array}$ & $\begin{array}{l}\text { Expt. } \\
\text { Group }\end{array}$ \\
\hline $\begin{array}{l}\text { Average No of MCQ questions } \\
\text { answered correctly after 2 } \\
\text { months }\end{array}$ & 2 & 5 \\
\hline $\begin{array}{l}\text { Average No of MCQ questions } \\
\text { answered correctly after 3 } \\
\text { months }\end{array}$ & 1 & 3 \\
\hline $\begin{array}{l}\text { Average No of MCQ questions } \\
\text { answered correctly after 6 month }\end{array}$ & 1 & 3 \\
\hline
\end{tabular}




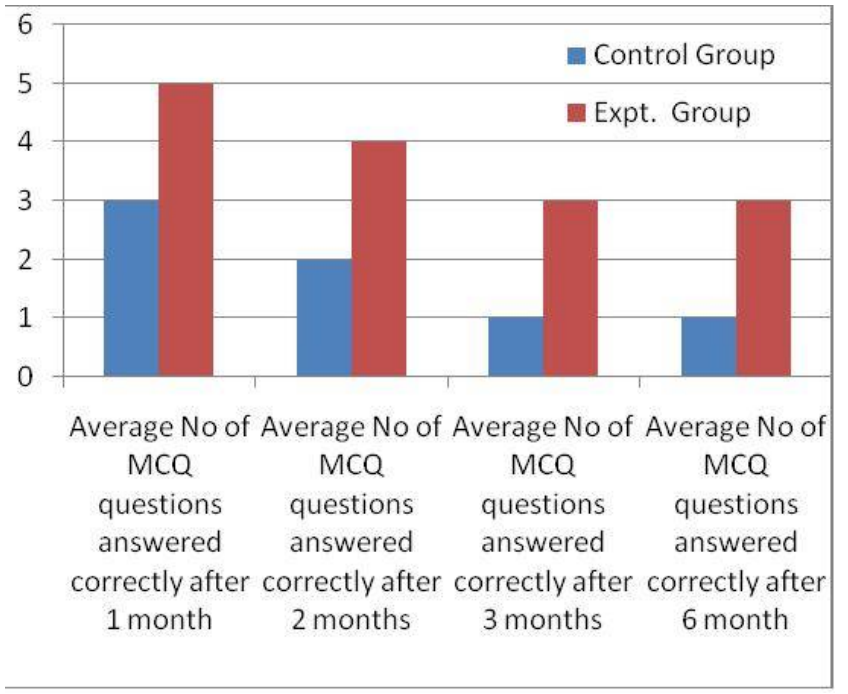

Figure 1: Impact Analysis of Innovative Teaching

\section{CONCLUSIONS}

The experimental results clearly indicate that the information and communication technology (ICT) based innovative teaching method like Use of Multimedia Animation makes high impact for long time duration compared to traditional teaching. The authors recommend that the teaching would be highly effective if it is outcome based and if the teachers start to use the recent innovative technologies like usage of animations, simulation, Power Point presentation, Models, flash, Audio-Visual tool etc. Also apart from technology there must be some sort of innovation like sense of humor, role playing, Z-A approach etc that can very well be practiced.

\section{Acknowledgement}

The authors are thankful to their affiliation institute DKTE Society's Textile and Engineering Institute, Ichalkaranji, Kolhapur, India for giving the permission to conduct the experiment. Authors are also thankful to all teaching and non teaching staff for their cooperation and fruitful discussion.

\section{References}

[1] Arunachalam, P. (2010) Higher Education Sector in India: Issues and Imperatives, Journal of Global Economy, 6(4), 266-286.
[2] McGee, S., Howard, B. (1998) Evaluating Educational multimedia in the context of use, Journal of Universal Computer Science, 4(3), 273-291.

[3] Doyle, W. (1983) Academic work, Review of educational research, 53(2), 159-199.

[4] Crocker, L., Algina, J. (1986), Introduction to classical and modern test theory, Holt, Rinehart and Winston, 6277 Sea Harbor Drive, Orlando, FL 32887.

[5] Orlich, D., Harder, R., Callahan, R., Trevisan, M., and Brown, A. (2012), Teaching strategies: A guide to effective instruction, Cengage Learning.

[6] Teo, R., Wong, A. (2000) Does problem based learning create a better student: A reflection, 2nd Asia Pacific Conference on Problem-Based Learning: Education Across Disciplines (pp. 4-7).

[7] Boud, D., Feletti, G. (1998), The challenge of problem-based learning, Psychology Press.

[8] Amidon, E. J., Flanders, N. A. (1971), The role of the teacher in the classroom, A manual for understanding and improving teacher classroom behavior, Association for Productive Teaching.

[9] Gardner, H. (2011). Frames of mind: The theory of multiple intelligences. Basic books.

[10] Snyder, S. J., Vaughan, M. J. (1998), Multimedia and Student Expectations. Developments in Business Simulation and Experiential Learning.

[12] Buzan, T., Buzan, B. (2010), Mind Map Book, 1 st edition, Rajpal \& Sons.

[14] Wood, D. F. (2003). Problem based learning. Bmj, 326(7384), 328-330.

[15] Osborn, A. F. (1953), Applied Imagination, Principles and procedures of creative thinking.

[16] Risk, T. M. (1958), Principles and practices of teaching in secondary schools. New York, American Book Company. 